\title{
Analysis of Weld Cold Cracking In Excavator Bucket Adapter
}

\author{
Wahidun Adam ${ }^{1}$, Pratjojo Dewo ${ }^{2}$, and Winarto Winarto ${ }^{1, *}$ \\ ${ }^{1}$ Department of Metallurgy and Materials Engineering, Universitas Indonesia, Depok, Indonesia \\ ${ }^{2}$ PT Komatsu Indonesia, Jakarta, Indonesia
}

\begin{abstract}
This paper presents a failure analysis on welding of bucket adapter for an excavator that made of low carbon steel with Ideal Diameter (DI) value 341 and Carbon Equivalent 0.73. The bucket component is stated $\mathrm{OK}$ as the final inspection, but four months later found cracked and even it has not been used yet. Adapter mounted to bucket through $\mathrm{CO}_{2}$ gas shielded Gas Metal Arc Welding (GMAW) process, filler metal MG-50 (AWS A5.18 ER70S-G), pre-heating and post-heating. Crack occurred on the boundary of weld metal and adapter casting. The metallurgical examination was conducted in the crack origin and the adapter casting. Nondestructive test (NDT) covered visual and magnetic test (MT), while destructive test (DT) covered fractography, mechanical properties, and Electron Probe Micro Analyzer (EPMA). The investigation resulted in that crack initiated from slag inclusion in the weld metal due to insufficient cleaning on weld joint. The higher hardness of martensite structure in the heat affected zone (HAZ) of adapter indicates high cooling rate that generates high residual stress. High stress that caused by insufficient post heating triggered severe crack propagation. By its characteristic, crack is called the cold cracking, delayed cracking, or hydrogen-induced cracking (HIC).
\end{abstract}

\section{Introduction}

The biggest problem in welding is crack, whether it is hot or cold cracking. Hot cracking is caused by a considerable portion of nonmetallic inclusion and a higher concentration of Phosphor (P) and Sulphur (S). Cold cracking is generated by the presence of little stresses arising from austenite to martensite transformation in the heat affected zone (HAZ). Minimizing of Sulphur, Phosphor, and nonmetallic inclusion provide low susceptibility to hot cracking, otherwise higher susceptibility to cold cracking [1]. Hot cracking obviously can be easily detected after weld finished. Cold crack, however, may appear a few days or even months after welding.

Cold cracking (CC) in actual steel structure counted more than $90 \%$ of weld crack case [2]. Cold cracking is known as hydrogen cracking or delayed crack, mostly occurs at a temperature below $200^{\circ} \mathrm{C}$ or immediately after welding, usually within 48 hours. Hydrogen gas $\left(\mathrm{H}_{2}\right)$ in the arc generated by moisture in consumable and material due to high temperature.

The hydrogen gas form very fine and subsurface hydrogen porosity in weld metal or may diffuses into HAZ that make it difficult to be detected [3]. Incubation time needed on crack development, so cold cracking also called "delayed crack." Three factors are acting synchronously in the formation of cold crack: hydrogen in the weld metal, high tensile residual stresses, and brittle microstructure, martensite [4].

In the past, cold cracking was most occured in high strength steel HAZ. The soundest and safest action to minimize the occurrence of cold cracking is sufficient preheating [5]. The minimum necessary preheating temperature for welding high strength steel determined by carbon equivalent (CE) as a steel weldability indicator. Carbon equivalent is proportional to hardenability, which means higher CE may result in higher hardness value of the HAZ that more susceptible to cold cracking. However, HAZ hardness can be lowered by applying sufficient preheating to allow low cooling rate [6]. Lately, the phenomenon of cold cracking in the steel welding process is affected by its chemical composition, thickness of parent metal, diffusible hydrogen content on weld metal, heat input, residual stresses, weld metal yield strength, weld joint restraint, notch concentration factor at weld root and weld toe, weld pass count, method of preheating (heating rate and width), ambient temperature, and instantanaeous post-heating [7]. Specifically, in thick welding plate

*Corresponding author: winarto@metal.ui.ac.id 
high strength low alloy (HSLA), controlling the cooling time at low temperature $\left(\mathrm{T}_{300}-\mathrm{T}_{100}\right)$ can be useful for preventing of cold cracking, with condition cooling time is longer than critical cooling time [8].

An excavator for digging purpose has a bucket with an adapter that mounts the ground engagement tool (GET) part called tooth. Adapter welded on plate lip by gas metal arc welding (GMAW) and $100 \%$ shielded by $\mathrm{CO}_{2}$ gas to insulate the weld pool from the atmosphere. Casting process used to produce an adapter from low alloy steel $4 \mathrm{~S}$ with a basic chemical composition (wt.\%): $\mathrm{C}=0.15$ $0.21 ; \mathrm{Si}=0.90-1.25 ; \mathrm{Mn}=1.08-1.48 ; \mathrm{Ni}=0.70-0.95$; $\mathrm{Cr}=0.95-1.25 ;$ and $\mathrm{Mo}=0.25-0.50$. While filler metal is MG-50 (AWS A5.18 ER70S-G) with the chemical composition (wt.\%): $\mathrm{C}=0.08 ; \mathrm{Si}=0.51$; $\mathrm{Mn}=1.10 ; \mathrm{Ni}=0.12 ; \mathrm{Cr}=0.10 ;$ and $\mathrm{Mo}=0.03$. The bucket component is lined with the specification but found cracked as received.

\section{Experimental Procedure}

First of all, visual examination and liquid penetrant test (LPT) of adapter weld have been made. One of the cracked adapters was taken by gas cutting with enough distance, about $100 \mathrm{~mm}$, to prevent structure changing near the crack line. Hacksaw cutting performed in both tip of a crack to observe the fracture surface (fractography), then small size (about 20x20 mm) sample taken from adapter casting and crack initiation site for chemical composition, mechanical properties, macroscopic observation, and microscopic observation. The chemical composition of adapter and weld metal measured by optical emission spectroscopy (OES) Shimadzu OES PDA-7000. Mechanical properties testing utilize Rockwell Hardness Tester Mitutoyo HR430MR on a rough surface and Micro Vickers Hardness Tester Mitutoyo HM220 on the polished sample. Macro and microscopic observation conducted in Stereo-microscope Keyence VHX5000 continued by an electron microscope (Electron Probe Micro Analyzer Shimadzu EPMA1720H) with high precision qualitative and quantitative analysis through wavelength dispersive spectrometry (WDS). The step of failure analysis has followed the literature [9].

\section{Result and Discussion}

\subsection{NDT Examination}

Some buckets showed Fig. 1a), that already installed on the excavator, found a crack on its adapter casting as seen in Fig. 1b). Interval time between fabrication process (welding) and crack finding reported four months. Due to crack characteristic visually similar, one of the buckets was destructed, and one adapter took by gas cutting with sufficient cooling in the crack area to avoid microstructure and properties change.

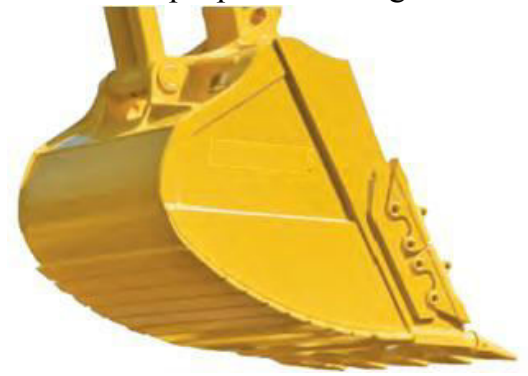

(a)

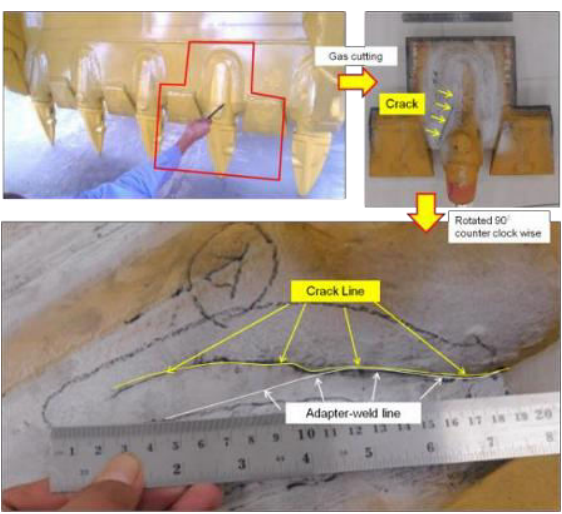

(b)

Fig. 1. (a) Attachment bucket in an excavator, failed (fracture) location (b, top) and its magnification adapter casting (b, bottom)

Magnetic test (MT) using white contrast paint conduct again for verifying report from the field. Length of crack measured about $165 \mathrm{~mm}$, with $80 \mathrm{~mm}$, is the boundary of weld metal-adapter casting and the rest in the adapter. VT on the crack line is not enough to determine the crack initiation site.

Visual examination on opened fracture surface (Fig. 2) show that there is a welding defect, i.e., gas porosity and weld slag/ inclusion, spotted on the first layer of welding. This inclusion can be caused by unclean of welding bead by the position in the root of weld metal. The presence of non-metallic inclusion and high concentration of Phosphor and Sulphur can cause hot cracking, instead of cold cracking [1]. The chemical composition of adapter and weld metal resulted in low Phosphor and Sulphur (below 0.025wt.\%) and ultrasonic testing (UT) result after 24 hours was good. So, possibilities of hot cracking can be eliminated. In another hand, cold cracking generally occurs at temperatures below $205^{\circ} \mathrm{C}$, but in some cases, these are initiated at a higher temperature and then grow- 


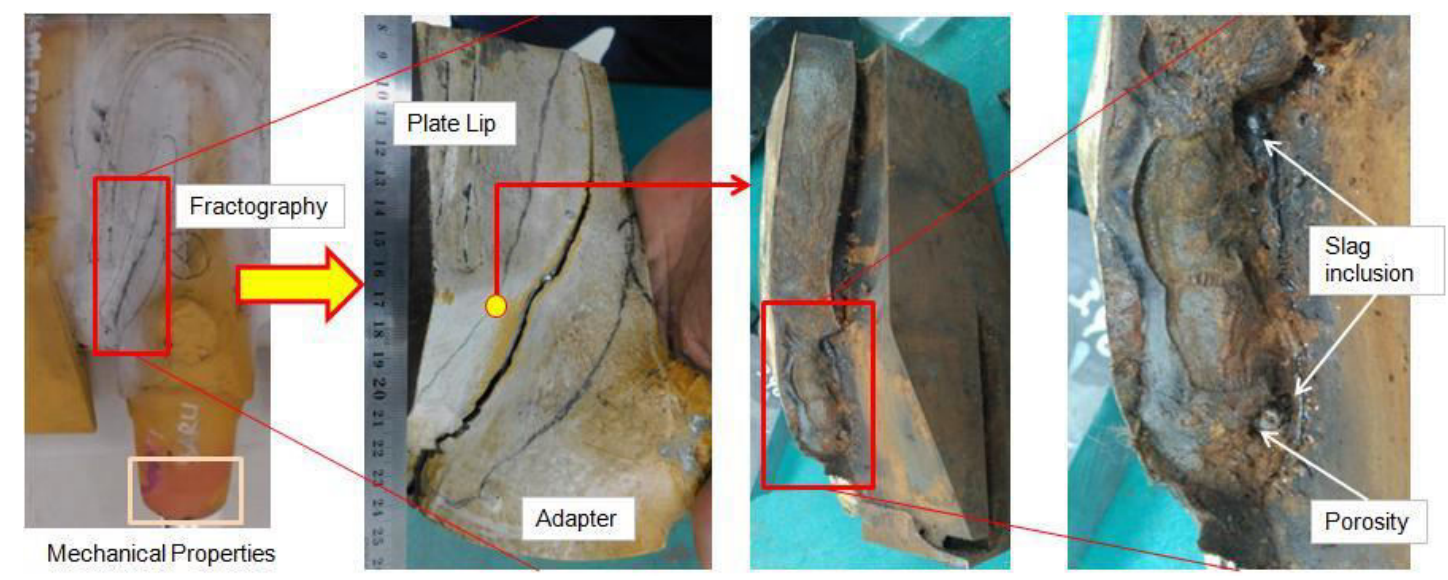

Fig. 2. Opened fracture by Electric Discharge Machine (EDM, wire cut) and fracture surface before cleaning

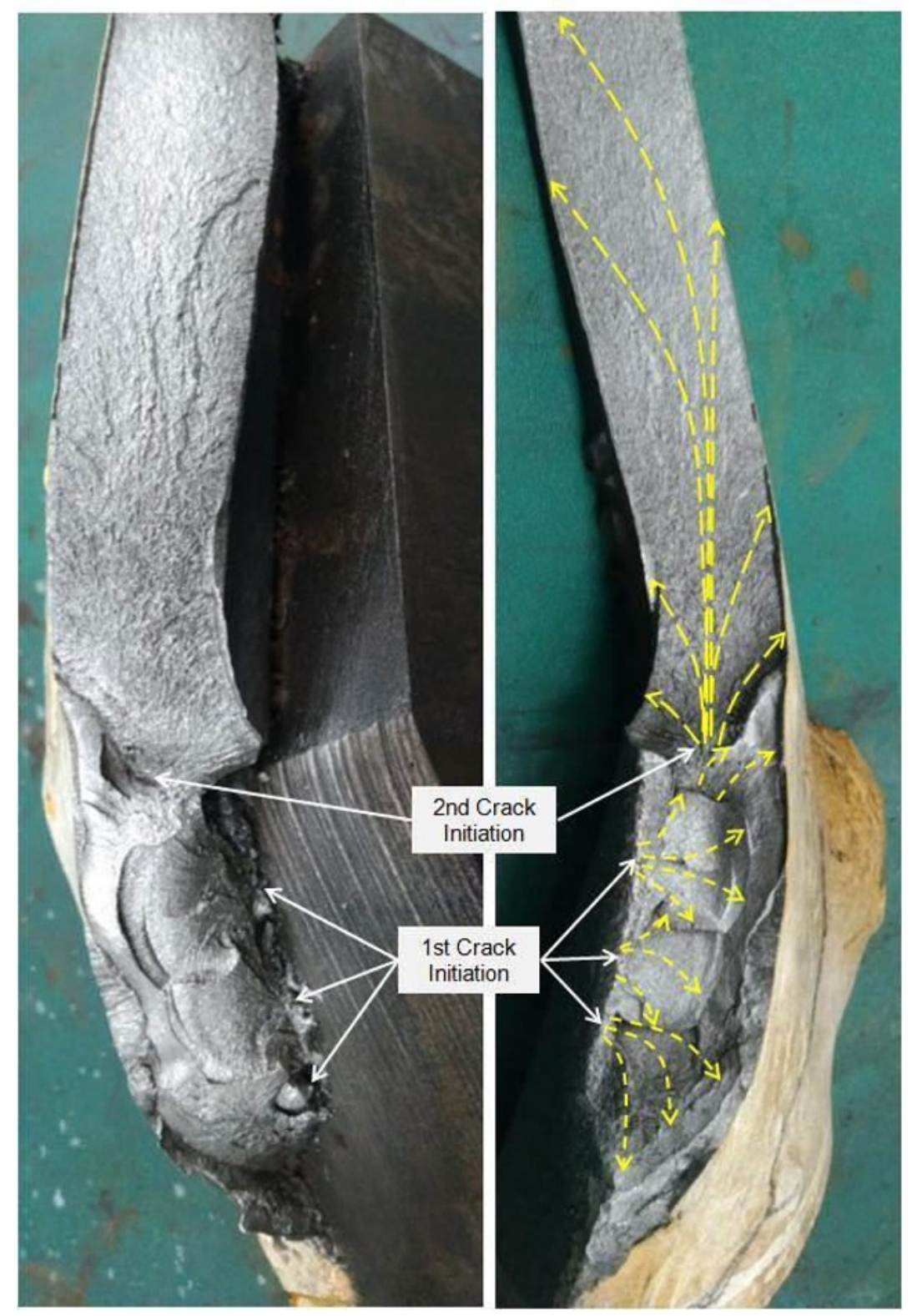

Fig. 3. Fracture surface pattern after cleaning 
to a detectable size at lower temperature [10]. Cracking may occur during cooling or after reaching room temperature. In this case, a crack occurred after an incubation time of 4 months and potential initiated from weld metal or HAZ. So, It is called a cold cracking or delay cracking [11]. Preheating and post-heating are the most effective way to let hydrogen diffuse out and reduce the level of residual stress [12].

\subsection{Fractography}

Fractography observation on the opened crack (Fig. 3 ) show that crack initiated first from weld area in the inclined side of the adapter. Then crack propagated to the surface and adapter casting area. Crack propagation mark by the yellow line in Figure 4.

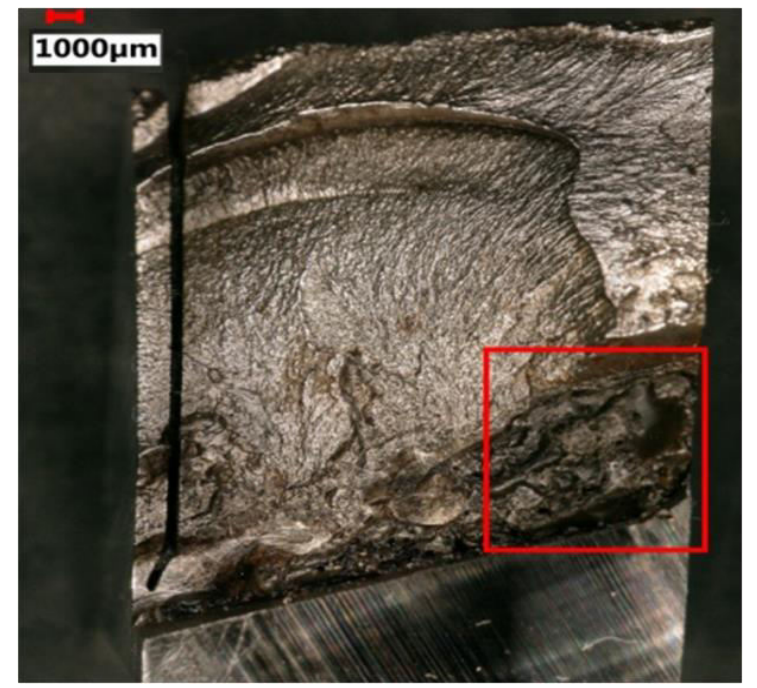

(a)

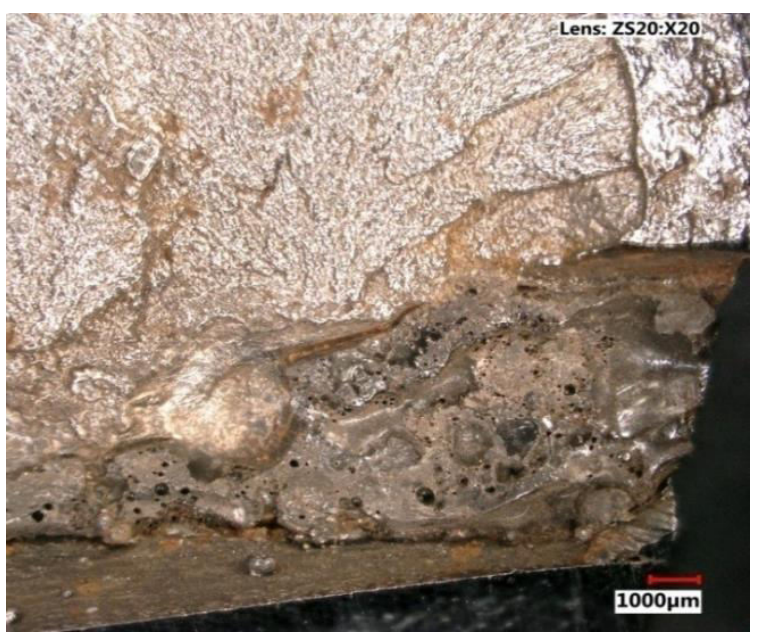

(b)

Fig. 4. (a) Piece of initiation area taken from fig. 3 left. (b) Magnification red square of slag inclusion in fig. $4 \mathrm{a}$.

Fracture mode identified as rapid or brittle fracture characterized by chevron pattern [13]. Since the bucket was not yet used, the stress comes from residual stress generated in the previous process, i.e., the welding process. Brittle fracture indicates that the component undergone overload even not yet applied to the external load. Three factors combine to produce cold crack: stress, hydrogen, and susceptible microstructure. High stresses may be generated by thermal expansion and contraction, or due to austenite-to-martensite transformation. Martensite structure is more vulnerable than ferritic and bainitic structure.

\subsection{Fracture Initiation Observation}

Weld defect in the initiation point, i.e., porosity and slag inclusion, found in the initiation area (fig. 5a) that is the boundary of filler metal, adapter casting, and plate lip (Fig. 4a \& 4b). Porosity may come from insufficient shield gas, inadequate preparation of weld joint, or porosity on adapter bead. Joining adapter to the bucket using $\mathrm{CO}_{2}$ Welding (GMAW) which the generation of slag should be avoidable.

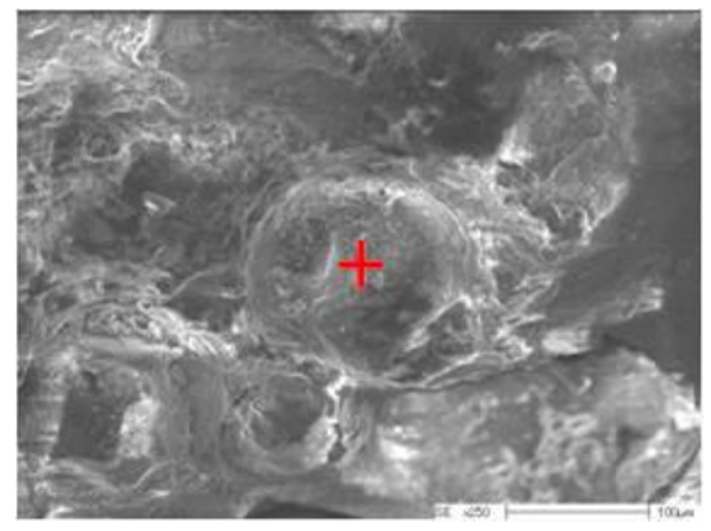

(a)

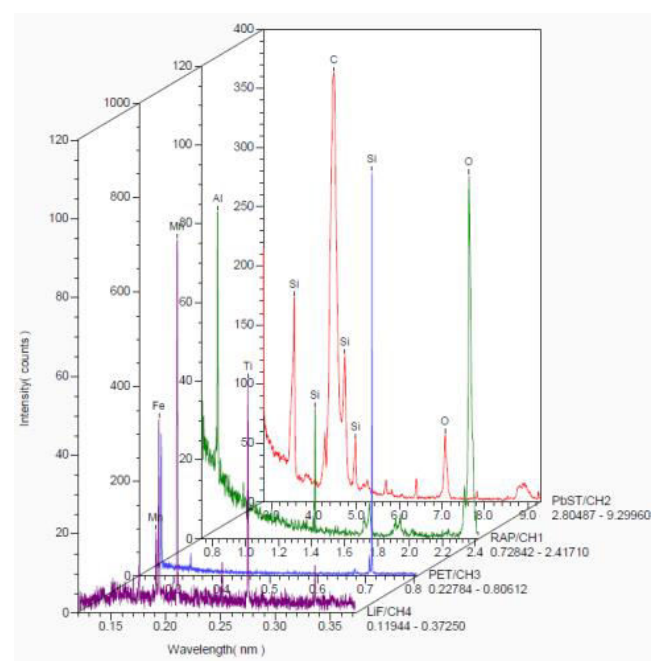

(b)

Fig. 5. Slag inclusion in fig. $4 \mathrm{~b}$ and its EPMA WDS spectrum 
Slag inclusions consist of nonmetallic materials trapped in the weld as a product of the slag reaction. Entrapment is the condition when slag mixing the weld pool or when surface slag is not removed completely and then buried by next weld passes. Slag may occur from an un-removed massive scale before welding. Slag inclusion can be located in the sub surface, inside of weld bead, or in the welding root like this case. Joining adapter use multiple-pass weld that is more prone to slag inclusion than single-pass weld joints due to slag may be entrapped in the weld between passed. Another common cause of entrapment is the incomplete removal of the slag from the previous pass. The higher rate of solidification/ cooling, lower temperature of weld pool, and undesired bead and joint shape are known as general factors triggering slag entrapment [12]. Image observation (Fig 5 \& 6) and qualitative analysis (Table $1 \& 2$ ) of slag inclusion in Fig 4b and its cross-section conducted by EPMA. Dominant element contained in slag inclusion is Carbon (C), Oxygen (O), and Silicon (Si). Slag inclusion not only found in the initiation area but also in the filler metal with the similar dominant element.

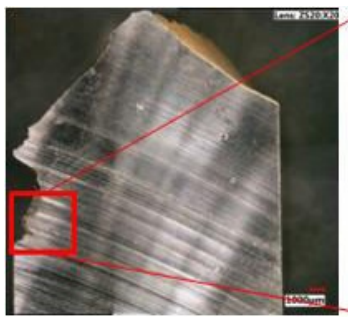

(a)

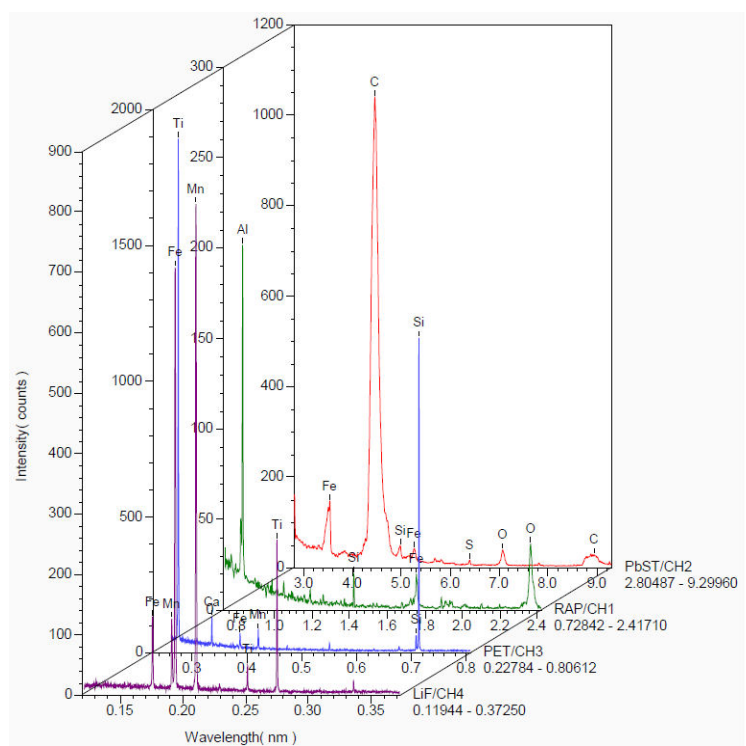

(c)

Fig. 6. (a) Cross section of initiation (b) Slag inclusion trapped in the weld metal. (c) EPMA WDS spectrum of slag inclusion
Table 1. Qualitative point analysis of slag fig. 5

\begin{tabular}{|rrrrrrr|}
\hline \multicolumn{2}{l}{ No. El ement Line } & Crystal & Peak WL $(\mathrm{nm})$ & K-ratio Mass\% \\
-1 & $\mathrm{C}$ & $\mathrm{Ka}$ & $\mathrm{PbST} / \mathrm{CH} 2$ & 4.47249 & 0.14961 & 22.38 \\
2 & 0 & $\mathrm{Ka}$ & $\mathrm{RAP} / \mathrm{CH} 1$ & 2.35952 & 0.53793 & 57.95 \\
3 & $\mathrm{Al}$ & $\mathrm{Ka}$ & $\mathrm{RAP} / \mathrm{CH} 1$ & 0.83008 & 0.00410 & 0.28 \\
4 & $\mathrm{Si}$ & $\mathrm{Ka}$ & $\mathrm{PET} / \mathrm{CH} 3$ & 0.71275 & 0.22874 & 14.14 \\
5 & $\mathrm{Ti}$ & $\mathrm{Ka}$ & $\mathrm{LiF} / \mathrm{CH} 4$ & 0.27492 & 0.02572 & 1.64 \\
6 & $\mathrm{Mn}$ & $\mathrm{Ka}$ & $\mathrm{LiF} / \mathrm{CH} 4$ & 0.21050 & 0.03587 & 2.41 \\
7 & $\mathrm{Fe}$ & $\mathrm{Ka}$ & $\mathrm{LiF} / \mathrm{CH} 4$ & 0.19369 & 0.01803 & 1.20 \\
\hline
\end{tabular}

Table 2. Qualitative point analysis of slag fig.6

\begin{tabular}{|rrrrrrr|}
\hline \multicolumn{2}{l}{ No. El ement Line } & Crystal & Peak WL $(\mathrm{nm})$ & K-ratio Mass\% \\
-1 & $\mathrm{C}$ & $\mathrm{Ka}$ & $\mathrm{PbST} / \mathrm{CH} 2$ & 4.46066 & 0.28238 & 41.34 \\
2 & 0 & $\mathrm{Ka}$ & $\mathrm{RAP} / \mathrm{CH} 1$ & 2.36302 & 0.10429 & 16.67 \\
3 & $\mathrm{Al}$ & $\mathrm{Ka}$ & $\mathrm{RAP} / \mathrm{CH} 1$ & 0.83162 & 0.00652 & 0.49 \\
4 & $\mathrm{Si}$ & $\mathrm{Ka}$ & $\mathrm{PET} / \mathrm{CH} 3$ & 0.71288 & 0.18167 & 12.20 \\
5 & $\mathrm{Ca}$ & $\mathrm{Ka}$ & $\mathrm{PET} / \mathrm{CH} 3$ & 0.33589 & 0.00449 & 0.27 \\
6 & $\mathrm{Ti}$ & $\mathrm{Ka}$ & $\mathrm{PET} / \mathrm{CH} 3$ & 0.27472 & 0.06941 & 4.50 \\
7 & $\mathrm{Mn}$ & $\mathrm{Ka}$ & $\mathrm{LiF} / \mathrm{CH} 4$ & 0.21038 & 0.18699 & 13.15 \\
8 & $\mathrm{Fe}$ & $\mathrm{Ka}$ & $\mathrm{LiF} / \mathrm{CH} 4$ & 0.19386 & 0.16424 & 11.39 \\
\hline
\end{tabular}

\subsection{Chemical composition}

The chemical composition of base metal and filler metal, not only to predicting its hardenability but also for determining suitable preheating temperature [14]. Sufficient preheat temperature able to control cooling rate and hardness of HAZ. The critical cooling rate for any metal depends on carbon equivalent (CE) which represent the effect of alloying element on weldability. The most famous equation to calculate $\mathrm{CE}$ given by International Institute of Welding (IIW) as Equation-1 [15]. Conditioning cooling time longer than the critical cooling time and controlling the cooling time at low temperature $\left(\mathrm{T}_{300}-\mathrm{T}_{100}\right)$ recommended to prevent cold cracking [8]. From chemical composition on Table 3, CE calculation for the adapter is 0.73 and filler metal 0.30. Based on Table 4, Adapter that has CE above 0.45, recommended being preheated at $204-371^{\circ} \mathrm{C}$. While the welding procedure of bucket fabricator state preheats temperature in the range of $150-230^{\circ} \mathrm{C}$, however, there is inconsistency in controlling cooling rate. Controlling cooling rate can use some media of cooling such as electric heater, blanket, and even air.

$$
C E(I I W)=C+\frac{M n}{6}+\frac{(C u+N i)}{15}+\frac{(C r+M o+V)}{5}(1)
$$

\subsection{Micro Observation}

Adapter belongs to high strength low alloy steel with ultimate tensile strength (UTS) $1200 \mathrm{MPa}$ and hardness 387-444 HBN, produced through casting and then quenched and tempered route. Steel is heated to austenitization temperature (about $850^{\circ} \mathrm{C}$ ) continued by rapid cooling in water to achieve a hard phase, martensite structure or at least bainite can be obtained. Hard and brittle nature of- 
Table 3. The chemical composition of the adapter and the filler metal

\begin{tabular}{|c|l|c|c|c|c|c|c|c|c|c|c|c|}
\hline \multirow{2}{*}{ Elements } & \multicolumn{10}{|c|}{ in wt.\% } \\
\cline { 2 - 14 } & & $\mathbf{C}$ & Si & Mn & P & S & Cu & Ni & Cr & Mo & Al & DI \\
\hline \multirow{2}{*}{$\begin{array}{c}\text { Adapter } \\
(4 S)\end{array}$} & $\mathrm{N}=1$ & 0,21 & 1,18 & 1,27 & 0,011 & 0,008 & 0,117 & 0,80 & 1,03 & 0,26 & 0,012 & 345 \\
\cline { 2 - 13 } & $\mathrm{N}=2$ & 0,21 & 1,16 & 1,26 & 0,011 & 0,009 & 0,117 & 0,80 & 1,03 & 0,26 & 0,013 & 336 \\
\cline { 2 - 13 } & Ave & 0,21 & 1,17 & 1,26 & 0,011 & 0,008 & 0,117 & 0,80 & 1,03 & 0,26 & 0,013 & 341 \\
\hline \multirow{2}{*}{$\begin{array}{c}\text { Weld } \\
\text { Metal } \\
(\text { MG 50) }\end{array}$} & $\mathrm{N}=1$ & 0,08 & 0,53 & 1,10 & 0,007 & 0,013 & 0,020 & 0,12 & 0,11 & 0,03 & 0,002 & 32 \\
\cline { 2 - 12 } & $\mathrm{N}=2$ & 0,08 & 0,49 & 1,10 & 0,007 & 0,011 & 0,020 & 0,11 & 0,09 & 0,03 & 0,003 & 30 \\
\cline { 2 - 12 } & Ave & 0,08 & 0,51 & 1,10 & 0,007 & 0,012 & 0,020 & 0,12 & 0,10 & 0,03 & 0,003 & 31 \\
\hline
\end{tabular}

quenched steel must be tempered in the range 480 $600^{\circ} \mathrm{C}$ or higher to obtain softer structure, i.e. tempered martensitic/ bainitic structure [16]. Martensite structure observed in the adapter casting (Fig. 7c), show that adapter had been treated by quench temper (QT).

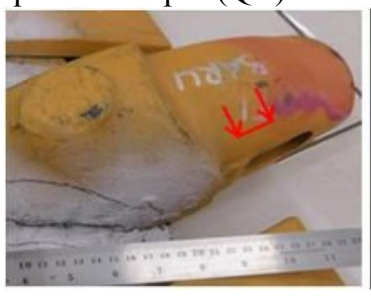

(a)

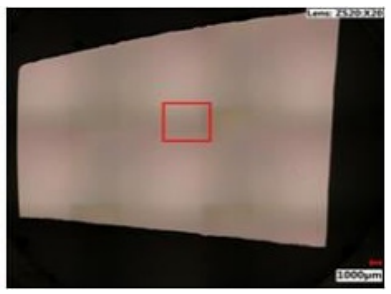

(b)

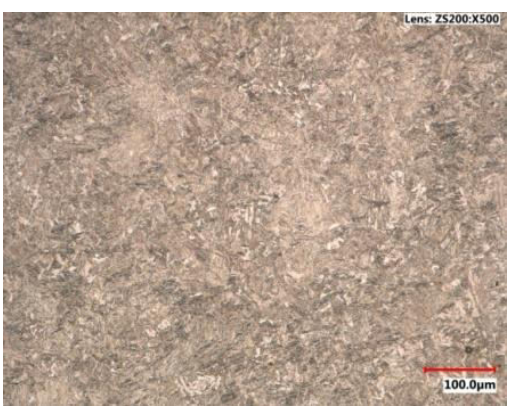

(c)

Fig. 7. (a) (b) Location for taking a microstructure specimen and (c) microstructure of adapter casting

\subsection{Hardness Test}

Hardness measurement through a cross-section of initiation area (Fig. 8) show fluctuation value with the abnormality occurred on the HAZ 2 adapter, which is much higher than HAZ 1 adapter (Fig. 9). The lower hardness of HAZ 1 adapter due to post heat effect of multilayer welding. However, HAZ 2 adapter whose position above HAZ 1 did not get sufficient post heating that makes cooling rate at this section is higher. As the effect, hardness becomes higher and residual stress due to phase transformation and weld shrink also higher.

Table 4. Preheat temperature for a different range of CE [17]

\begin{tabular}{|c|c|}
\hline $\begin{array}{c}\text { Carbon Equivalent } \\
(\%)\end{array}$ & Recommended Treatment \\
\hline$<0.30$ & Preheat optional \\
\hline 0.30 to 0.45 & $\begin{array}{c}\text { Preheat at } 200(93) \text { to } 400 \\
(204){ }^{\circ} \mathrm{F}\left({ }^{\circ} \mathrm{C}\right)\end{array}$ \\
\hline$>0.45$ & $\begin{array}{c}\text { Preheat at } 400(204) \text { to } \\
\end{array}$ \\
\hline
\end{tabular}

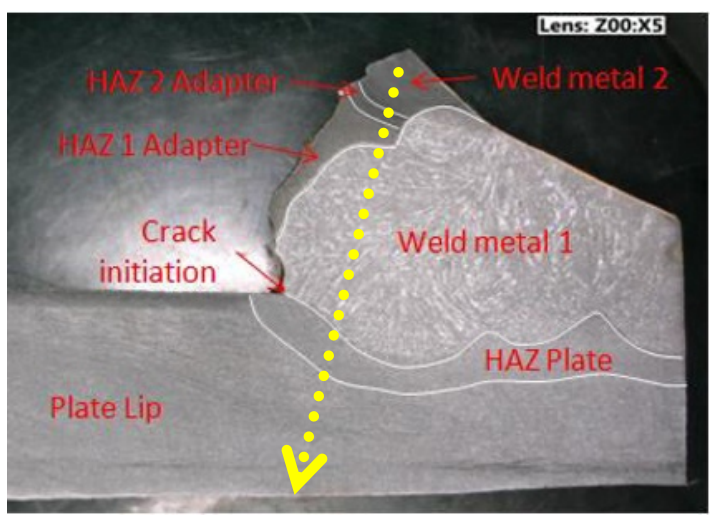

Fig. 8. Nital $30 \%$ macro etching on the cross section of initiation

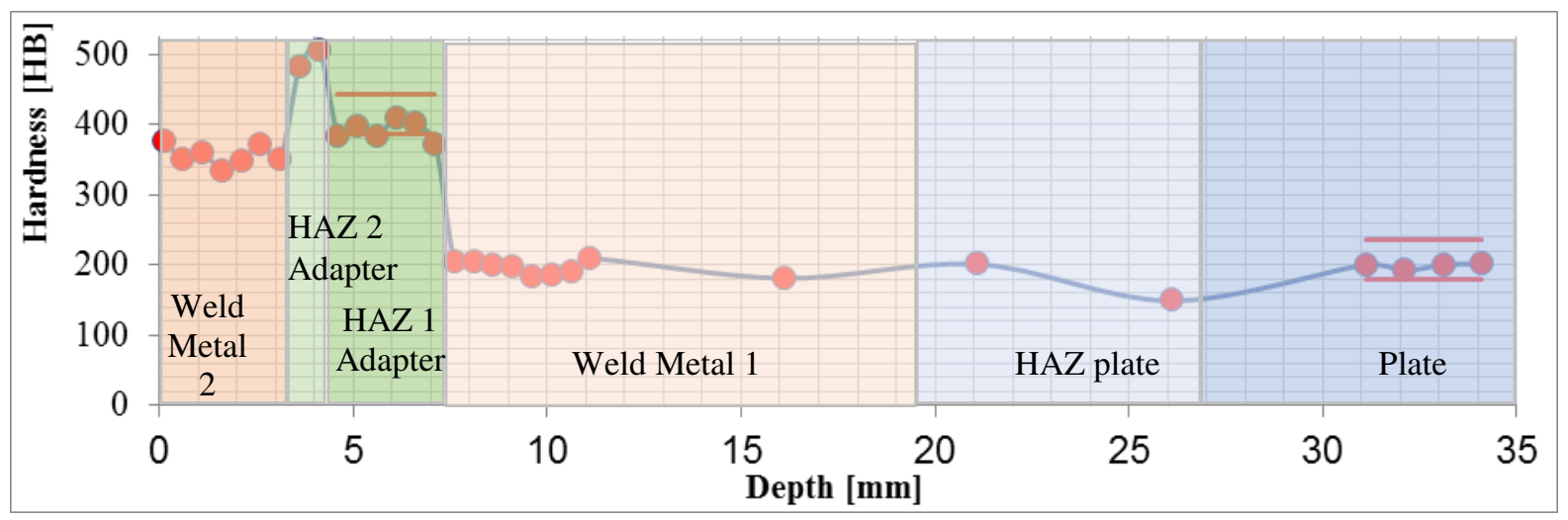

Fig. 9. Hardness value for location in fig. 8 


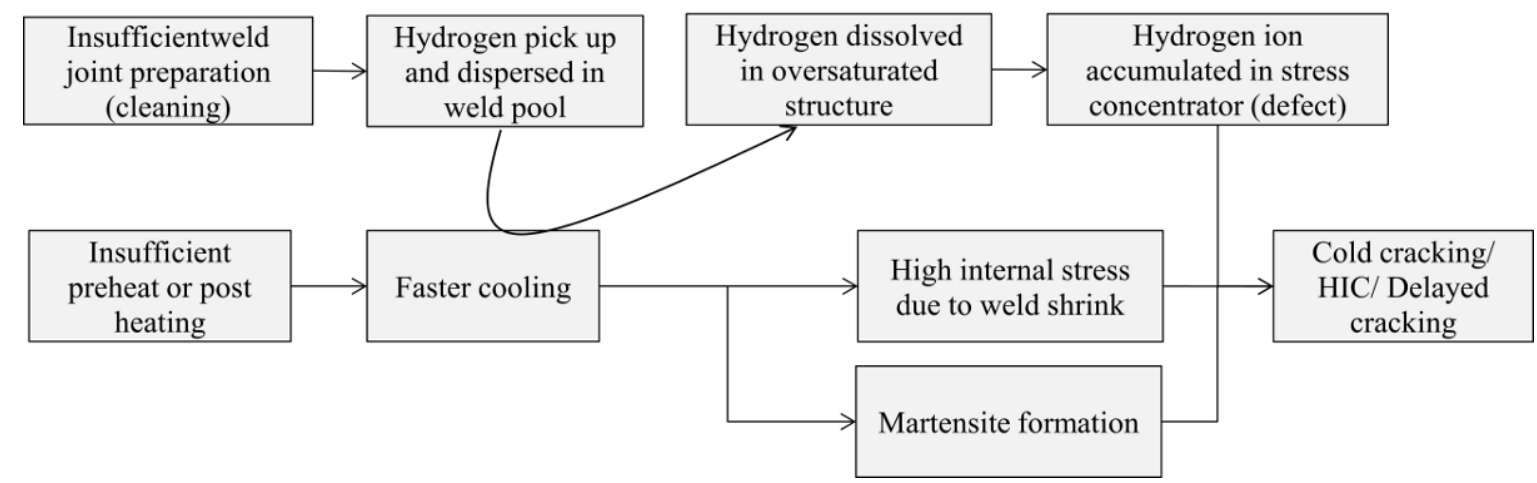

Fig 10. Estimation of failure mechanism

\section{Conclusion}

The failure of excavator bucket adapter is cared for by cold cracking or delayed cracking. Crack initiated from slag inclusion in the root of weld metal caused by insufficient weld joint preparation and cleaning of the previous pass. The higher hardness of martensite structure in the heat affected zone (HAZ) of the adapter was due to a high cooling rate. High stress caused by insufficient post heating and inconsistency of controlling cooling rate triggered severe crack propagation.

The authors acknowledge the support of research funding from the Directorate of Research and Community Service of Universitas Indonesia through the PITTA Program 2018 with the Contract No. 2559/UN2.R3.1/HKP.05.00/2018

\section{References}

1. Opiela, M. (2010). Hydrogen embrittlement of welded joints for the heat-treatable XABO 960 steel heavy plates. Journal of Achievements in Materials and Manufacturing Engineering 38, 41-48.

2. Weld metal hydrogen cracking in pipeline Girth welds. (1999). Proc. 1st Int. Conf. Wollongong, Australia: HM Hart, Granta Park, Great Abington.

3. Service, W. S. (2000). Defect-hydrogen cracks in steels-prevention and best practice. The Welding Institute.

4. Kou, S. (1987). Welding Metallurgy. New York: John Wiley and Sons.

5. Yurioka, N. (2001). ISIJ Int., 566-570.

6. Nobutaka Yurioka, T. K. (1995). Weld in the world 5, 31-38.

7. Yurioka, N. (2004). Comparison of preheating predictive method. Welding in the World, vol. 48, 21-27.

8. Winarto and M. Anis (2011). Cooling rate control on cold cracking in welded thick HSLA steel plate. Materials Science Forum,
689, 269-275.

9. Aliya, D. (2002). The Failure Analysis Process: An Overview. In A. H. Committee, ASM Handbook vol. 11: Failure Analysis and Prevention (pp. 667-682). ASM International.

10. Beachum, E. (1961). Hydrogen and Delayed Cracking in Steel Weldments. Weld, J., Vol 40, 155-159.

11. E. G. Signes, P. H. (1988). Weld. J, 163-170.

12. John Layer, e. a. (2002). Failures Related to Welding. In e. a. John Layer, ASM Handbook vol 11: Failure Analysis and Prevention (pp.358-360). ASM International.

13. Voort, G. F. (1987). Visual Examination and Light Microscopy. In A. H. Committee, Fractography, volume 12 (pp. 203-2015). New York: ASM International.

14. Funderburk, R. S. (1997). Key Concepts in Welding Engineering - Fundamentals of Preheat. Welding Innovation Vol. XIV, 2.

15. Tadashi Kasuya, N. Y. (1995). Methods Of Predicting Maximum Hardness Of Heat Affected Zone And Selecting Necessary Preheat Temperature For Steel Welding. Nippon Steel Technical Report, No 65.

16. R. Datta, D. M. (2002). Weldability characteristics of shielded metal arc welded high strength quenched and tempered plate. Journal of Materials Engineering and Performance 11, 5-10.

17. Som Dutt Sharma, R. S. (2013). A Review On Effect of Preheating and Post Weld Heat Treatment (PWHT) on Hardened Steel. International Journal of Technical Research and Applications, Vol. 1, 05-07 